\title{
Gallbladder perforation associated with carcinoma of the duodenal papilla: a case report
}

\author{
Akihiro Hosaka*, Mikiko Nagayoshi, Katsuyoshi Sugizaki and Yukiyoshi Masaki
}

\begin{abstract}
Background: Gallbladder perforation is a rare clinical condition, which mostly occurs following acute cholecystitis associated with cholelithiasis. A tumor of the ampulla of Vater causes gradually progressive symptoms, and is rarely associated with perforation of the gallbladder.

Case Presentation: A 56-year-old man with carcinoma of the ampulla of Vater presented with spontaneous gallbladder perforation and localized bile peritonitis. He complained of right upper abdominal pain, and laparotomy revealed perforation of the gallbladder with no gallstones. Postoperative upper gastrointestinal endoscopy demonstrated a slightly enlarged duodenal papilla, and biopsy revealed adenocarcinoma of the ampulla. Pyloruspreserving pancreaticoduodenectomy was performed subsequently.

Conclusion: Ampullary carcinoma can be associated with gallbladder perforation and present with acute manifestations. Immediate surgical treatment is required for this condition.
\end{abstract}

\section{Background}

Gallbladder perforation (GBP) is a rare but life-threatening condition, which usually requires immediate surgical intervention. Most cases are complicated by acute cholecystitis associated with cholelithiasis [1], although acute acalculous cholecystitis or intramural vessel thrombosis can sometimes lead to GBP $[2,3]$.

A tumor of the ampulla of Vater causes gradually progressive symptoms such as jaundice or weight loss, and rarely presents with acute manifestations [4-6]. In this report, we describe a case of ampullary carcinoma presenting with acute development of GBP and bile peritonitis, and discuss the clinical features of the disease.

\section{Case Presentation}

A 56-year-old man was referred to our hospital with right upper abdominal pain, which had worsened over the previous two days. He had been free of symptoms previously. He had a history of moderate smoking and alcohol consumption, and no appreciable medical or family history. On admission, his body temperature was $37.4^{\circ} \mathrm{C}$. Blood examination showed a white blood cell count of 8900 /

* Correspondence: hosaka-a@umin.ac.jp

1 Department of Surgery, Ome Municipal General Hospital, 16-5, Higashi Ome 4-chome, Ome-shi, Tokyo, 198-0042, Japan

Full list of author information is available at the end of the article $\mathrm{mm}^{3}$, C-reactive protein level of $0.08 \mathrm{mg} / \mathrm{dl}$, total bilirubin level of $0.6 \mathrm{mg} / \mathrm{dl}$, aspartate aminotransferase level of $57 \mathrm{IU} / \mathrm{l}$, and alanine aminotransferase level of $67 \mathrm{IU} / \mathrm{l}$. Computed tomography (CT) and echography demonstrated distention of the gallbladder and thickening of its wall and dilatation of the common bile duct, but no gallstones were detected (Fig 1).

He was diagnosed with acute cholecystitis, and initially treated with fluid resuscitation and administration of antibiotics. However, the abdominal pain did not improve, and laparotomy was performed the day after admission, which revealed biliary ascites around the gallbladder and partial necrotic change in the neck and body of the gallbladder. We performed cholecystectomy and intraoperative cholangiography, which revealed no stones in the gallbladder and bile duct. The postoperative course was uneventful. Pathological examination of the resected gallbladder revealed inflammatory change of its wall, and no arterial occlusive change (Fig 2a). Microbiological test of the bile showed negative results. Upper gastrointestinal endoscopy performed postoperatively showed slight enlargement of the duodenal papilla. Adenocarcinoma of the papilla was diagnosed by biopsy, and pylorus-preserving pancreaticoduodenectomy (PPPD) was performed 6 weeks after the first surgery. Intraoperative findings revealed slight dilatation of the common bile duct, and a 


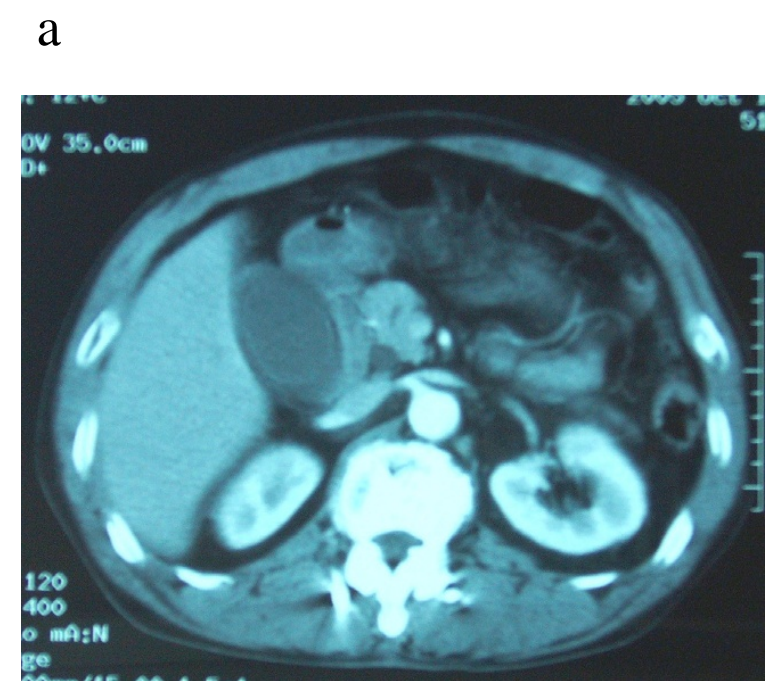

b

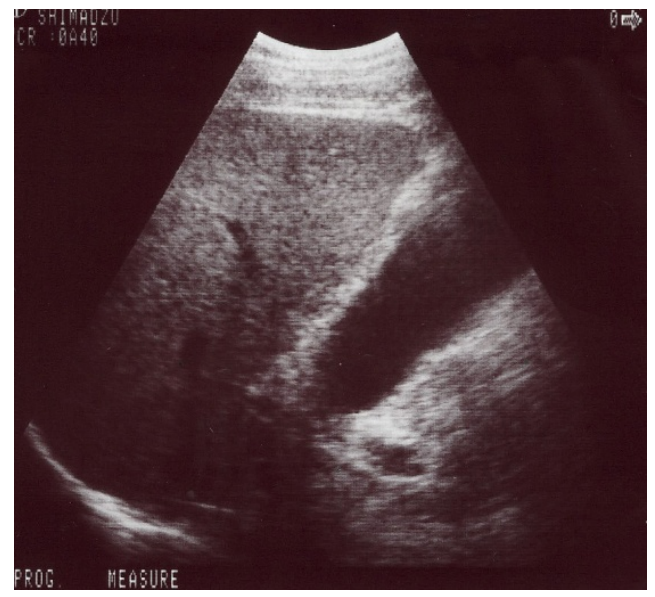

Figure 1 Preoperative imaging findings. Preoperative computed tomography (a) and echography (b) show distention of the gallbladder and thickening of its wall.

soft pancreas with normal pancreatic duct. Pathological examination of the resected specimens demonstrated well-differentiated tubular adenocarcinoma with a maximum diameter of $1.3 \mathrm{~cm}$ localized in the papilla, with no lymph node metastasis, classifying the tumor as TNM stage IA (T1NOM0) (Fig 2b,c). Minor pancreatic leakage occurred during the postoperative course, which was treated conservatively. The patient has been free of recurrence during the 4-year follow-up after surgery.

\section{Discussion}

It has been reported that GBP occurs in about $5 \%$ of patients with acute cholecystitis [1,7]. Ischemic changes of the gallbladder wall triggered by progression of local inflammation lead to gangrene and perforation, which

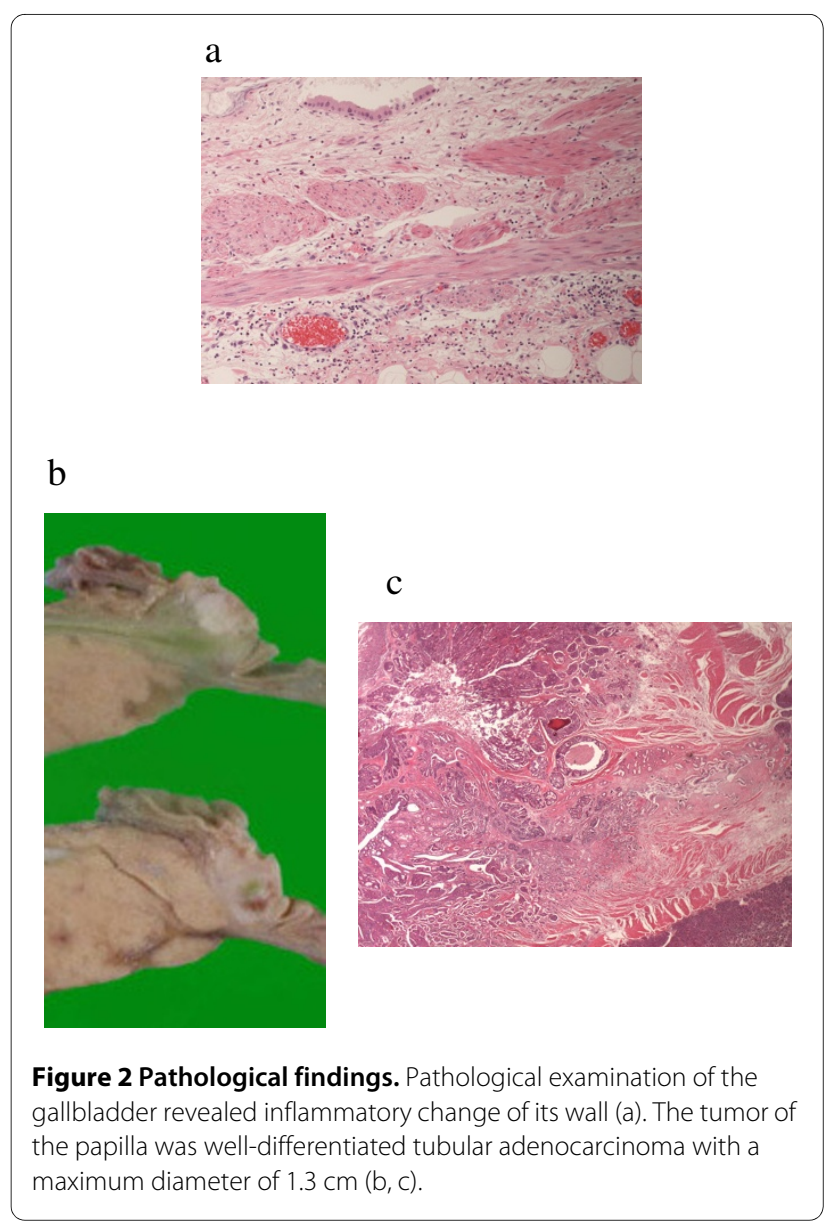

might explain why perforation occurs in the fundus, the most distant part from the main feeding artery, in more than half of cases. Systemic vascular disorders, such as atherosclerotic cardiovascular disease and diabetes, immunosuppressed states, and malignancy are major risk factors for GBP [1]. Most cases of GBP follow an exacerbation of acute cholecystitis with cholelithiasis, and GBP without gallstones is rare. Such cases are mainly attributed to impairment of the blood supply induced by intramural thrombosis [3]. In our patient, who had no underlying risk factor for GBP, no stones were found in the gallbladder, and postoperative pathological examination revealed no thrombotic occlusion of intramural vessels, which is extremely uncommon. The cause of GBP remains unclear. It might have been induced by acute progression of cholecystitis, although the causal relationship between the ampullary tumor and GBP is not obvious.

Preoperative diagnosis of GBP is often difficult, which delays surgical intervention and leads to high morbidity and mortality [1,7]. CT and ultrasonography are useful in making the diagnosis. Gallbladder wall thickening, pericholecystic fluid collection, and a streaky omentum or mesentery are common findings of GBP [1,7-9]. However, 
accurate diagnosis of a defect in the gallbladder wall is rather challenging. CT has been reported to be more sensitive than ultrasonography in detecting a perforation site in the gallbladder [1,8], while Sood et al. [9] reported that a defect in the gallbladder wall could be visualized in more than $70 \%$ of cases either by CT or ultrasonography, and suggested the latter as the first-line imaging modality in the evaluation of suspected GBP cases. In our patient, the defect in the gallbladder wall and the amount of leaked bile were small, which made preoperative diagnosis difficult.

Obstructive jaundice is the most common presentation of carcinoma of the papilla, followed by weight loss, abdominal pain, and nausea [4-6]. The disease usually shows gradual progression of these symptoms, and rarely displays an acute clinical onset. Associated GBP, as in our patient, is extremely uncommon. The prognosis of ampullary carcinoma is relatively better than that of other biliary tract cancers after surgical resection [10]. Lymph node metastasis and pancreatic invasion are important prognostic factors [4,11]. Beger et al. [12] reported that lymph node involvement was observed in about $10 \%$ of patients with a pT1 carcinoma of the papilla. Therefore, Kausch-Whipple procedure or PPPD with lymph node dissection is the first choice of treatment even in patients with localized cancer, although local resection might be beneficial in patients with a poor general condition $[12,13]$.

\section{Conclusion}

Although extremely rare, carcinoma of the duodenal papilla can be associated with GBP and display acute manifestations. In a case of GBP without cholelithiasis, ampullary tumor should be considered as a possible underlying condition.

\section{Consent}

Written informed consent was obtained from the patient for publication of this case report and accompanying images. A copy of the written consent is available for review by the Editor-in-Chief of this journal.

\section{Competing interests}

The authors declare that they have no competing interests.

\section{Authors' contributions}

$\mathrm{AH}$ participated in the treatment of the patient, collection of case details, literature search and drafted the manuscript. MN, KS, and YM participated in the treatment of the patient and data collection, and helped to revise the manuscript. All authors have read and approved the final manuscript.

\section{Author Details}

Department of Surgery, Ome Municipal General Hospital, 16-5, Higashi Ome 4chome, Ome-shi, Tokyo, 198-0042, Japan

Received: 18 February 2010 Accepted: 20 May 2010

Published: 20 May 2010
References

1. Derici H, Kara C, Bozdag AD, Nazli O, Tansug T, Akca E: Diagnosis and treatment of gallbladder perforation. World J Gastroenterol 2006, 12:7832-6.

2. Wang AJ, Wang TE, Lin CC, Lin SC, Shih SC: Clinical predictors of severe gallbladder complications in acute acalculous cholecystitis. World J Gastroenterol 2003, 9:2821-3.

3. Namikawa T, Kobayashi M, Okabayashi T, Okamoto K, Akimori T, Sugimoto T, Hanazaki K: Clinicopathological analysis of idiopathic perforation of the gallbladder. Surg Today 2007, 37:633-7.

4. Beger HG, Treitschke F, Gansauge F, Harada N, Hiki N, Mattfeldt T: Tumor of the ampulla of Vater: experience with local or radical resection in 171 consecutively treated patients. Arch Surg 1999, 134:526-32.

5. Madjov R, Chervenkov P: Carcinoma of the papilla of Vater. Diagnostic and surgical problems. Hepatogastroenterology 2003, 50:621-4.

6. Kamisawa T, Tu Y, Egawa N, Nakajima H, Horiguchi S, Tsuruta K, Okamoto A: Clinicopathologic features of ampullary carcinoma without jaundice. J Clin Gastroenterol 2006, 40:162-6.

7. Menakuru SR, Kaman L, Behera A, Singh R, Katariya RN: Current management of gall bladder perforations. ANZ J Surg 2004, 74:843-6.

8. Kim PN, Lee KS, Kim IY, Bae WK, Lee BH: Gallbladder perforation: comparison of US findings with CT. Abdom Imaging 1994, 19:239-42.

9. Sood BP, Kalra N, Gupta S, Sidhu R, Gulati M, Khandelwal N, Suri S: Role of sonography in the diagnosis of gallbladder perforation. J Clin Ultrasound 2002, 30:270-4.

10. Ishihara S, Miyakawa S, Takada T, Takasaki K, Nimura Y, Tanaka M, Miyazaki M, Nagakawa T, Kayahara M, Horiguchi A: Status of surgical treatment of biliary tract cancer. Dig Surg 2007, 24:131-6.

11. Moriya T, Kimura W, Hirai I, Mizutani M, Ma J, Kamiga M, Fuse A: Nodal involvement as an indicator of postoperative liver metastasis in carcinoma of the papilla of Vater. J Hepatobiliary Pancreat Surg 2006, 13:549-55.

12. Beger HG, Thorab FC, Liu Z, Harada N, Rau BM: Pathogenesis and treatment of neoplastic diseases of the papilla of Vater: KauschWhipple procedure with lymph node dissection in cancer of the papilla of Vater. J Hepatobiliary Pancreat Surg 2004, 11:232-8.

13. Kobayashi A, Konishi M, Nakagohri T, Takahashi S, Kinoshita T: Therapeutic approach to tumors of the ampulla of Vater. Am J Surg 2006, 192:161-4.

doi: 10.1186/1477-7819-8-41

Cite this article as: Hosaka et al., Gallbladder perforation associated with carcinoma of the duodenal papilla: a case report World Journal of Surgical Oncology 2010, 8:41

\section{Submit your next manuscript to BioMed Centra} and take full advantage of:

- Convenient online submission

- Thorough peer review

- No space constraints or color figure charges

- Immediate publication on acceptance

- Inclusion in PubMed, CAS, Scopus and Google Scholar

- Research which is freely available for redistribution

Submit your manuscript at www.biomedcentral.com/submit
C Biomed Central 